\title{
The Synchronous Primary Carcinomas of the Rectum and Thymus
}

\author{
Taner BABACAN ${ }^{1}$, Sait DAG ${ }^{2}$, Furkan SARICI ${ }^{1}$, Ismail DILLI ${ }^{2}$, \\ Ibrahim H. TURKBEYLER ${ }^{3}$, Kadri ALTUNDAG ${ }^{1}$
}

\author{
${ }^{1}$ Department of Medical Oncology, Hacettepe University Institute of Oncology, Ankara \\ ${ }^{2}$ Department of Internal Medicine, Gaziantep University Faculty of Medicine, Gaziantep \\ ${ }^{3}$ Department of Internal Medicine, Adıyaman University Faculty of Medicine, Adıyaman, TURKEY
}

\section{Dear Editor,}

Thymomas are rare neoplasm arising in thymic epithelial cells and are the most common neoplasm in the anterior mediastinum. Although thymomas are often associated with autoimmune diseases, the incidence of extra-thymic neoplasia is higher in patients with thymoma than in the general population. ${ }^{1}$ Published series have focused on the incidence of both extra-thymic malignancies detected after and before the diagnosis of thymoma. In this case report we are presenting a patient operated due to synchronous rectal cancer and malign thymoma diagnosis. To the best of our knowledge, this is the first case presented with synchronous rectal cancer and malign thymoma.

A 56-year-old female with hematemesis and pelvic pain was admitted to the gastroenterology outpatient department. A flexible rectoscopic examination revealed a rigid and painful mass encircled the lumen of rectum. A biopsy of the rectal mass confirmed a well-differentiated adenocarcinoma of rectum. Laparoscopic low anterior resection was performed and the tumor extended through the layers of the bowel wall and pericolic fatty tissue, not reaching the serosal surface. Twenty lymph nodes dissected from the pericolic fatty tissue and ten lymph nodes were diagnosed as metastatic rectal adenocarcinoma. Due to mediastinal mass observation in posterioanterior graphy in the post-operation period, the Thorax CT was initiated. In the analysis, a lobulated $5 \times 4 \mathrm{~cm}$ sized enhancing mass and a lot of lymphadenopathy was found in anterior mediastinum. Also in PET CT analysis, a mass lesion evoking malignancy was found in anterior mediastinum. In order to make metastasis and second primary tumor differential diagnosis, trucut biopsy was initiated. Since the biopsy results were consistent with the malign thymoma, we have initiated the mass excision lymph node dissection. Pathology results revealed invasive thymoma and reactive lymph node. Final diagnosis was made as synchronous double malignancies; an adenocarcinoma of rectum with a clinical stage of T3N2bM0 and an invasive thymoma of the thymus with a clinical stage of B1. In order to treat rectal cancer, radiotherapy was given to anterior mediastinum following the initiation infusional 5-FU-based radio-chemotherapy. After then, adjuvant FOLFOX-4 therapy was started for the treatment of rectal cancer.

The thymus plays an important role in both autoimmunity and cancer immunosurveillance. When there is depression of T-cell immunity, the incidence of cancer increases. Several series have confirmed an increased incidence of thymoma and additional neoplasms, with prevalence rates as high as $31 \% .^{2}$ Welsh and colleagues ${ }^{1}$ reported that $28 \%$ of 136 patients with thymoma acquired extra-thymic cancers. The most common extra-thymic cancer in their series was colorectal carcinoma. Pan and coworkers ${ }^{3}$ reported a series of 192 patients with thymoma from Taiwan. 
The incidence of extra-thymic neoplasm was $8 \%$, and the most common tumor was gastric adenocarcinoma. To understand the lifetime risk and incidence of extra-thymic neoplasia in patients with thymoma, Weksler et al. ${ }^{4}$ evaluated extra-thymic neoplasms diagnosed either before or after the diagnosis of thymoma.

They queried the Surveillance, Epidemiology, and End Results (SEER) cancer database and identified patients with thymoma and extra-thymic neoplasms. The most common extra-thymic cancers in this study were lymphoma, breast cancer, prostate cancer, lung cancer, and colorectal cancer. In this study extra-thymic cancers were present before the diagnosis of thymoma in 88 patients, 12 patients had diagnoses of extra-thymic primary cancers both before and after the diagnosis of thymoma, and 206 patients had 227 extra-thymic primary tumors diagnosed after the thymoma was diagnosed. Published series have focused on the incidence of both extra-thymic malignancies detected after and before the diagnosis of thymoma. There are some cases presented in literature concerning synchronous colon carsinoma and malign thymoma. ${ }^{5}$ This is the first case in literature presented with synchronous rectal cancer and malign thymoma. In the differential diagnosis of mediastinal mass in patients diagnosed with rectal cancer, malign thymoma need to be considered beside metastasis.

\section{REFERENCES}

1. Engels EA. Epidemiology of thymoma and associated malignancies. J Thorac Oncol 5: 260-265, 2010.

2. Welsh JS, Wilkins KB, Green R et al. Association between thymoma and second neoplasms. JAMA 283: 1142-1143, 2000.

3. Pan CC, Chen PC, Wang LS, et al. Thymoma is associated with an increased risk of second malignancy. Cancer 92: 24062411, 2001

4. Weksler B, Nason K.S.,MPH, Mackey D et al. Thymomas and Extrathymic Cancers Ann Thorac Surg 93: 884-889, 2012.

5. Welsh JS, Thurman SA, Howard SP Thymoma and Multiple Malignancies: A Case of Five Synchronous Neoplasm and Literature Review Clin Med Res 3: 227-232, 2003.

\section{Correspondence}

Dr. Ibrahim Halil TURKBEYLER

Gaziantep Üniversitesi Tıp Fakültesi

Iç Hastalıkları Anabilim Dalı

Şahinbey, GAZIANTEP / TURKEY

Tel: +904162233815

e-mail: turkbeyler@mynet.com 